\title{
IDENTIFICATION OF THE AGE RELATED SKIN CHANGES USING HIGH-FREQUENCY ULTRASOUND
}

\author{
Kozarova $\mathrm{A}^{1}$, Kozar $\mathrm{M}^{2}$, Minarikova $\mathrm{E}^{1}$, PaPPova $\mathrm{T}^{1}$ \\ ${ }^{1}$ Dermatovenerology Clinic, Jessenius Faculty of Medicine in Martin, Comenius University in Bratislava, \\ University Hospital Martin, Slovakia \\ ${ }^{2}$ Neonatology Clinic, Jessenius Faculty of Medicine in Martin, Comenius University in Bratislava, \\ University Hospital Martin, Slovakia
}

\begin{abstract}
Skin aging has become an area of increasing research interest in dermatovenerology. Changes in the skin associated with aging can be detected by high - frequency $20 \mathrm{MHz}$ ultrasonography, which is a useful diagnostic technique allowing reliable imaging of cutaneous and superficial subcutaneous structures.

Skin thickness is considered an objective parameter providing assessment of the influence of endogenous or exogenous factors, such as ultraviolet (UV) or infrared (IR) rays. Except for the changes in the skin thickness, there are also specific structural changes in the dermis of older subjects - subepidermal low echogenic band (SLEB) - that is a manifestation of photoaging severity. The main aim of this study was to identify and characterize the specific ultrasonographic changes of the cutaneous structure related to age and degree of photo exposure (the presence and measurement of SLEB).
\end{abstract}

Key words: High-frequency $20 \mathrm{MHz}$ ultrasonography, skin thickness, photoaging, subepidermal low-echogenic band

\section{INTRODUCTION}

Several techniques have been used for measurement of skin thickness and structural changes in the skin. In clinical practice, mild-frequency ultrasonography (range 7.5-15 MHz) is widely used for investigation of lymph nodes. Ultrasonography with frequency of $20 \mathrm{MHz}$ allows reliable imaging of cutaneous and superficial subcutaneous structures up to a depth of maximally $7 \mathrm{~mm}$, but the epidermal structures can not be clearly visualized. In contrast, transducers with ultrasound frequency of $100 \mathrm{MHz}$ and $150 \mathrm{MHz}$ are able to provide an image of fine epidermal structure without the possibility to show dermal and subdermal area. High-frequency $(20 \mathrm{MHz})$ ultrasonography represents a painless alternative to skin biopsy. Measuring of skin thickness using an A-mode device was performed for the first time by Alexander and Miller in 1979 (1).

Cutaneous aging is divided into two components: intrinsic and extrinsic aging. Intrinsic aging is the natural aging process and is genetically determined and characterized by physiologic alterations of the skin structure. It is characterized by three features: dermal atrophy due to collagen loss, degeneration of the elastic fibre network and loss of hydration. These changes lead to thinning of the skin $(2,3)$. Extrinsic aging is caused by exposure to UV radiation and is more commonly called photoaging. The term photoaging describes distinct clinical, histological and functional features of chronically sunexposed skin. Photoaged skin has a characteristic histological appearance - elastosis that generally begins at the junction of papillary and reticular dermis, the replacement of mature collagen fibers by collagen with a distinct basophilic appearance, a large increase in deposition of glycosaminoglycans, fragmented elas-

Address for correspondence:

MUDr. Andrea Kozárová, Dermatolovenerology Clinic, University Hospital, Kollárova 2, 03601 Martin, Slovakia

e-mail: andrejka.kozarova@gmail.com 
tic fibers and dermal extracellular matrix proteins such as elastin (4). The UV light induces an extensive accumulation of water in the papillary dermis and hypertension in the venous system $(5,6)$. All these factors cause the changes in dermal echogenicity. In 1989 de Rigal et al. (7) showed that a low echogenic band-like structure is present in the subepidermal region of photoaged skin.

The main aim of this study was the identification and characterization of the specific ultrasonographic skin structure changes related to the age of subjects.

\section{METHODS}

One hundred subjects were enrolled into the study (50\% males and $50 \%$ females). Participants were divided into two age groups: group 1 consisting of 50 subjects aged $67.3 \pm$ 1.8 years and group 2 including the same number of subjects aged $23.9 \pm 0.8$ years. These groups were further divided into four subgroups according to gender: group A (25 females aged $67.3 \pm 1.8 \mathrm{yrs}$ ), group B ( 25 females aged $23.9 \pm 0.8 \mathrm{yrs}$ ), group C ( 25 males aged $67.4 \pm 1.7 \mathrm{yrs}$ ) and group D (25 males aged $23.9 \pm 0.8 \mathrm{yrs})$.

The study was performed in Dermatovenerology Clinic, Jessenius Faculty of Medicine and University Hospital in Martin from January 2014 to December 2016. The high resolution 20 $\mathrm{MHz}$ ultrasound imaging equipment (Dermascan $\mathrm{C}^{\circledR}$, Cortex Technology, Denmark) was used to obtain cross sectional images of the skin (B-mode). The axial resolution of the equipment was $50 \mu \mathrm{m}$, lateral resolution $300 \mu \mathrm{m}$ and maximum measurable depth was $7.0 \mathrm{~mm}$. The ultrasonic wave is partially reflected at the boundary between adjacent structures and generates echoes of a defined amplitude. The intensity of the reflection echoes is evaluated by the microprocessor and visualized on a colored two-dimensional image. The coloured scale of echogenicity is white> yellow> red > green> blue> black.

Skin ultrasonography was performed in vivo on the dorsal forearm and at the ventral thigh. Probands were informed about the nature and purpose of the study and a written consent was obtained.

The thickness of skin was defined as the distance between the epidermal entrance echo and hypoechogenic area below the green dermis. Two values of each area were measured and the mean thickness was calculated. Measurement of the region of SLEB was marked with a cursor by hand outlining of the subepidermal low-echogenic area. SLEB thickness was defined as a hypoechogenic black area between the epidermis and dermis. The main thickness of the SLEB was calculated from three various sites gained from each image.

The data were statistically analysed using Shapiro-Wilk normality test to determine the distribution of individual parameters, Mann Whitney-U test to compare the skin thickness and ttest to identify the difference in SLEB thickness between groups. Values of $\mathrm{p} \leq 0.05$ were considered statistically significant.

\section{RESULTS}

Median skin thickness of the dorsal forearm was $1.21 \mathrm{~mm}$ (IQR 1.10-1.32 mm) and $1.39 \mathrm{~mm}$ (IQR 1.29-1.59 mm) and skin thickness of the ventral thigh was $1.32 \mathrm{~mm}$ (IQR $1.19-1.47 \mathrm{~mm}$ ) and $1.54 \mathrm{~mm}$ (IQR 1.39-1.65 mm) in group 1 (50 subjects aged $67.3 \pm 1.8$ yrs) and group 2 (50 subjects aged $23.9 \pm 0.8$ yrs), respectively. Results showed significant differences between these groups in skin thickness in both areas (p<0.0001) (Fig 1).

Similar results were found in both forearm and thigh skin thickness comparing subgroups of probands according to gender. There was a significant difference in the forearm $(\mathrm{p}<0.006)$ and thigh skin thickness ( $\mathrm{p}<0.003$ ) between group A and B (females) as well as between group $\mathrm{C}$ and $\mathrm{D}$ (males). Complete descriptive statistics is denoted in Table 1. 
Fig. 1 Comparison of forearm and thigh skin thickness between groups of probands according to their age. 1-Group 1, 2-Group 2, * * $\mathrm{p}<0.0001$.

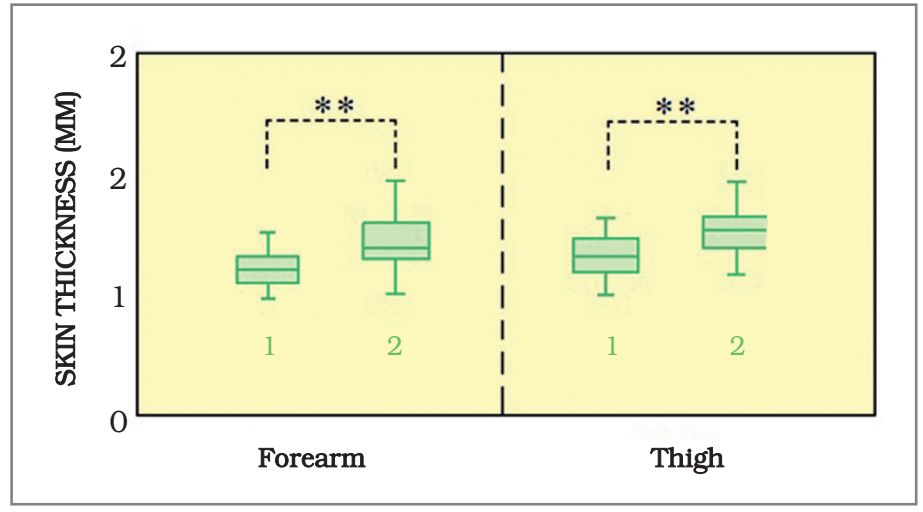

Table 1. Comparison of forearm and thigh skin thickness between groups - descriptive statistics.

\begin{tabular}{|c|c|c|c|c|c|c|}
\hline \multirow{2}{*}{ GROUP } & LOCATION & $\mathbf{n}$ & AM (mm) & Median (mm) & SD (mm) & IQR (mm) \\
\hline \multirow{2}{*}{1} & $\mathrm{~F}$ & 50 & 1.23 & 1.21 & 0.15 & $1.10-1.32$ \\
\cline { 2 - 7 } & $\mathrm{T}$ & 50 & 1.33 & 1.32 & 0.18 & $1.19-1.47$ \\
\cline { 2 - 7 } & $\mathrm{F}$ & 50 & 1.45 & 1.39 & 0.26 & $1.29-1.59$ \\
\hline \multirow{2}{*}{$\mathrm{A}$} & $\mathrm{T}$ & 50 & 1.59 & 1.54 & 0.35 & $1.39-1.65$ \\
\cline { 2 - 7 } & $\mathrm{F}$ & 25 & 1.16 & 1.13 & 0.13 & $1.09-1.30$ \\
\hline \multirow{2}{*}{$\mathrm{B}$} & $\mathrm{T}$ & 25 & 1.25 & 1.25 & 0.14 & $1.13-1.34$ \\
\cline { 2 - 7 } & $\mathrm{F}$ & 25 & 1.40 & 1.39 & 0.25 & $1.24-1.54$ \\
\hline \multirow{2}{*}{$\mathrm{C}$} & $\mathrm{T}$ & 25 & 1.53 & 1.43 & 0.34 & $1.37-1.58$ \\
\cline { 2 - 7 } & $\mathrm{F}$ & 25 & 1.29 & 1.27 & 0.15 & $1.13-1.44$ \\
\hline \multirow{2}{*}{$\mathrm{D}$} & $\mathrm{T}$ & 25 & 1.41 & 1.46 & 0.17 & $1.29-1.58$ \\
\cline { 2 - 7 } & $\mathrm{F}$ & 25 & 1.66 & 1.54 & 0.35 & $1.44-1.73$ \\
\hline
\end{tabular}

F - Forearm, T - Thigh, $\mathrm{n}$ - number of probands, AM - Arithmetic mean, SD - Standard Deviation, IQR Interquartile Rate

In group of older probands (group 1) a SLEB on the dorsal forearm was visualized and measured (Fig. 2). SLEB was not present on the ventral part of thigh (Fig. 3). The thickness of SLEB was $0.38 \pm 0.12 \mathrm{~mm}$ and $0.38 \pm 0.09 \mathrm{~mm}$ in group $\mathrm{A}$ and group $\mathrm{C}$, respectively. No significant difference was found between males and females in the SLEB thickness (Fig. 4). 


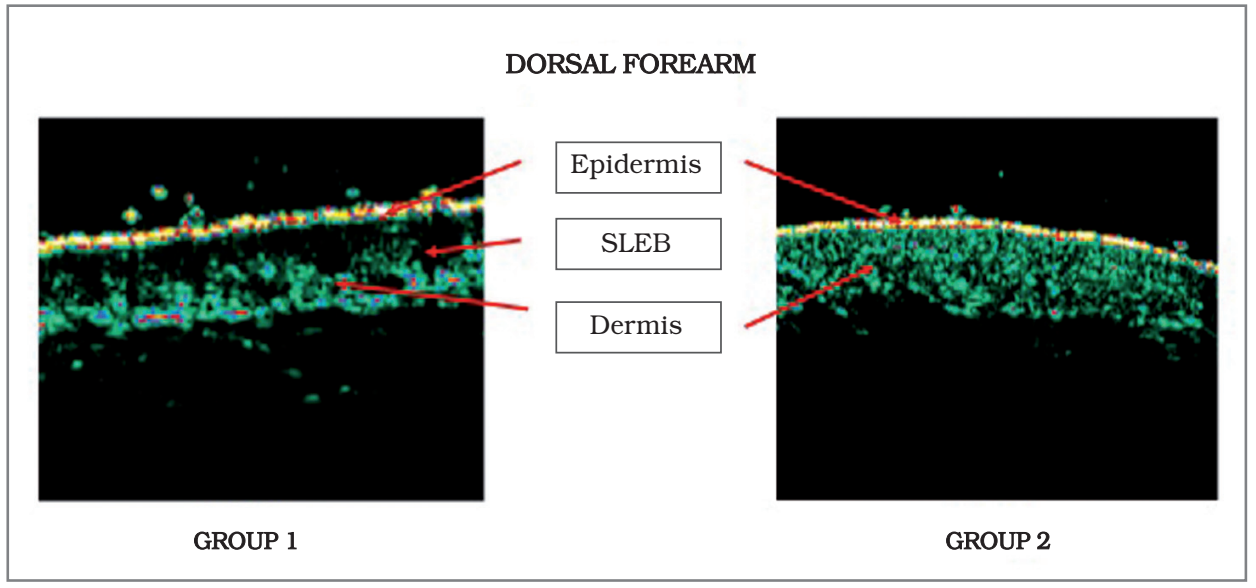

Fig. 2

Ultrasonograp hic image of the dorsal forearm in group 1 and group 2.

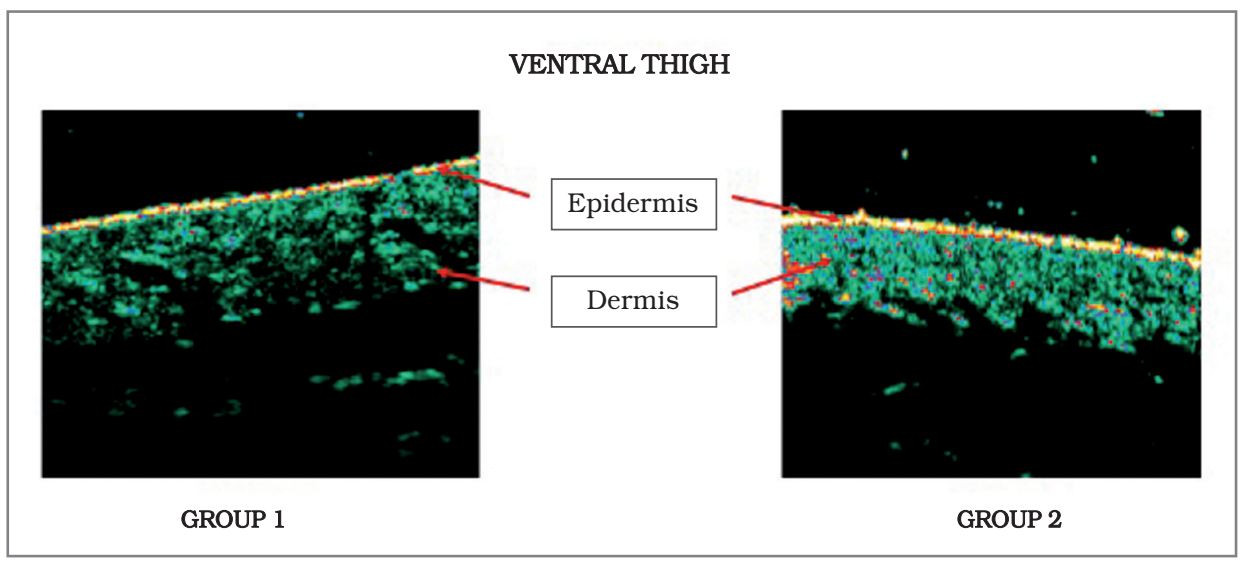

Fig. 3

Ultrasonograp hic image of the ventral thigh in group 1 and group 2 .

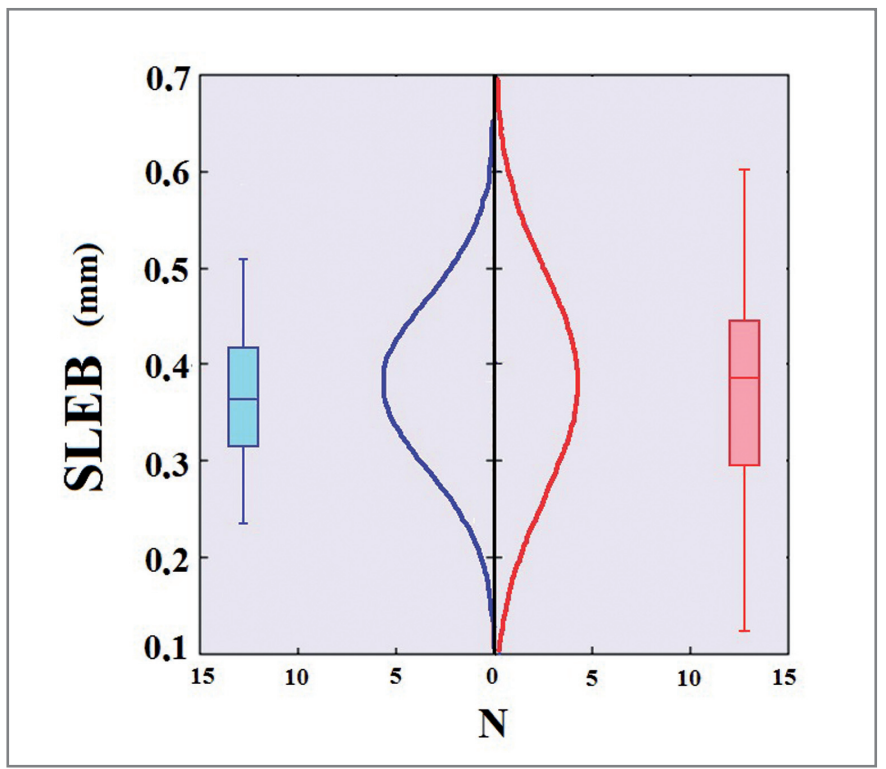

Fig. 4 Comparsion between the SLEB thickness at dorsal forearm of group A (red colour) and group B (blue colour), $\mathrm{N}$ - number of probands. 


\section{DISCUSSION}

High-frequency ultrasonography is a method of imaging with multiple indications in clinical and experimental dermatology. The main applications are following: measurement of the preoperative malignant melanoma thickness, investigation of benign and malignant tumors and inflammatory processes of the skin and the subcutis (psoriasis, atopic dermatitis, etc.), evaluation and monitoring of scleroderma-like diseases and T-cell lymphomas treatment $(8,9)$. The ultrasonographic images of changes in the thickness and structure of the skin allow an objectification of aging and skin damage.

Studies have shown that the thickness of whole skin has a tendency to increase in the 21- to 40-year interval and decreases after 60 - 70 years of age $(2,10,11,12)$. Histological examination of the skin sample acquired from old subject revealed increased amount of glycosaminoglycans and proteoglycans and decrease of collagen fibers. The thinning of the skin with aging is a consequence of a decrease in dermal collagen synthesis $(2,13)$. Our results shown that the skin thickness of both investigated areas was significantly thinner in probands older than 65 years of life. Our results are consistent with literature in the field $(2,14,15)$.

It has been discovered that skin is thinner in the areas chronically exposed to sunlight compared with the photoprotected areas regardless the skin age (15). Authors explain this phenomenon by increasing amount of glycosaminoglycans and proteoglycans in the dermal ground substance and decrease of collagen fibers $(2,13)$. Similarly, our results showed that ventral thigh skin (without chronic exposure to UV rays) was thicker in both groups than dorsal forearm skin.

Except for the changes in the thickness the specific structural changes in the dermis of older subjects are present. During the ultrasonographic investigation SLEB with various thickness can be seen. Studies have revealed that SLEB becomes visible mainly after the 21 - to 40 -year interval, especially on photoexposed sites $(2,16,17,18)$. De Rigal et al. (7) concluded that the SLEB thickness was higher on the dorsal forearm - a site of chronic exposure to UV rays than on volar forearm, which suggested that SLEB reflects mainly photodamage. In our study SLEB was present in all 50 subjects aged > 65 years only on the dorsal forearm (Fig. 2). Our results did not show significant difference in SLEB thickness between males and females and are consistent with the results of the available literature (18).

\section{CONCLUSION}

In conclusion - according to our results - the intrinsic ageing does not result in SLEB formation, but SLEB is a manifestation of UV radiation and measurement of its thickness is an objective marker of the photoaging process. The skin is thinner with the age and thinner on the sites of chronic exposure of UV rays. The thinning of the skin is mainly a manifestation of natural aging.

The measurement of skin thickness and knowledge of the age related skin changes is important to objectify treatment response in many skin disorders as psoriasis, atopic dermatitis, the skin atrophy after chronic steroid therapy and the evaluation of the efficacy of various topical anti-aging therapies.

\section{REFERENCES}

1. Alexander H, Miller DL. Determining skin thickness with pulsed ultrasound. J Invest Dermatol 1979; 72:17-9.

2. Crisan D, Lupsor M, Boca A, Crisan M, Badea R. Ultrasonographic assessment of skin structure according to age. Indian J Dermatol Venereol Leprol 2012; 78: 519.

3. Uitto J. The role of elastin and collagen in cutaneous aging: Intrinsic aging versus photoexposure. J Drugs Dermatol 2008; 7: 12-6. 
4. Berneburg M, Plettenberg H, Krutmann J. Photoaging of human skin. Photodermatol Photoimmunol Photomed 2000; 16: 239-244.

5. Gniadecka M. Localisation of dermal oedema in lipodermatosclerosis, lymphoedema and cardiac insufficiency. J Am Acad Dermatol 1996; 35: 37-41.

6. Serup J, Keiding J, Fullerton A, et al. High-frequency examination of the skin: introduction and guide. In: Serup J, Jemec GBE, eds. In vivo examination of skin: handbook of noninvasive methods. Boca Raton: CRC Press, 1995: 239-256.

7. de Rigal J, Escoffer C, Querleux B, Faivre B, Agache P, Lévê que JL. Assessment of aging of the human skin by in vivo ultrasonic imaging. J Invest Dermatol 1989; 93: 621-624.

8. Dill - Müller D, Masche J. Ultrasonography in dermatology. JDDG 2007; 5:689-707.

9. Polańska A, Dańczak-Pazdrowska A, Silny W, Sadowska A, Jenerowicz D, Osmola-Mańkowska A, OlekHrab K. High-frequency ultrasonography in monitoring the effects of treatment of selected dermatoses. Dermatol Alergol 2011; XXVIII, 4: 255-260.

10. Dumas M, Langle S, Noblesse E, Bonnet-Duquennoy M, Pelle de Gueral D, Tadokoro T, et al. Histological variation of Japanese skin with aging. Int J Cosmet Sci 2005; 27: 47-50.

11. Ha RY, Nojima K, Adams WP Jr, Brown SA. Analysis of facial skin thickness: Defining the relative thickness index. Plast Reconstr Surg 2005; 115: 1769-73.

12. Takema Y, Yorimoto Y, Kawai M, Imokawa G. Age-related changes in the elastic properties and thickness of human facial skin. Br J Dermatol 1994; 131: 641-8.

13. Affinito P, Palomba S, Sorrentino C, Di Carlo C, Bifulco G, Arienzo MP, et al. Effects of postmenopausal hypoestrogenism on skin collagen. Maturitas 1999; 33: 239-47.

14. Escoffier C, de Rigal J, Rochefort A, Vasselet R, Lévêque JL, Agache PG. Age-related mechanical properties of human skin: an in vivo study. J Invest Dermatol. 1989 Sep; 93(3): 353-7.

15. Pellacani G, Seidenari S. Variations in facial skin thickness and Echogenicity with site and age. Acta Derm Venerol 1999;79:366- 9.

16. Gniadecka M, Gniadecki R, Serup J, Søndergaard J. Ultrasound structure and digital image analysis of the subepidermal low-echogenic band in aged human skin: diurnal changes and interindividual variability. J Invest Dermatol 1994 Mar; 102 (3): 362-5.

17. Hoffman K, Dirschka TP, Stücker M, el-Gammal S, Altmeyer P. Assessment of actinic skin damage by $20 \mathrm{MHz}$ sonography. Photodermatol Photoimmunol Photomed. 1994 Jun; 10(3): 97-101.

18. Seidenari S, Pagnoni A, Di Nardo A, Giannetti A. Echographic evaluation with image analysis of normal skin: variation according to age and sex. Skin Pharmacol. 1994; 7(4): 201-209.

Received: February, 2, 2017

Accepted: March, 14, 2017 